\title{
Antenatal Marijuana Use Is Unrelated to Sexually Transmitted Infections During Pregnancy
}

\author{
Joseph M. Miller, Jr.,* and Christina Goodridge \\ Department of Obstetrics and Gynecology, Louisiana State University Health Sciences Center, \\ New Orleans, LA
}

\begin{abstract}
Objective: This study evaluated the relationship between marijuana use and sexually transmitted diseases in pregnant women.

Methods: A retrospective review of clinic records over a 12-1/2 month period identified all women entering prenatal care. Eighty-six women using no illicit substance other than marijuana were compared to 441 drug-free women. The prevalence of gonorrhea, chlamydia, syphilis, human immunodeficiency virus, hepatitis B surface antigen, human papilloma virus, and herpes was ascertained.

Results: No significant differences were found in the prevalence of any single sexually transmitted disease between pregnant women who used marijuana and drug-free pregnant women. When the presence of one or more sexually transmitted disease was considered, again no difference was found.

Conclusion: Marijuana use was not associated with sexually transmitted disease in pregnant women. Infect. Dis. Obstet. Gynecol. 8:155-157, 2000. () 2000 Wiley-Liss, Inc.

KEY WORDS

cannabis; chlamydia; gonorrhea
\end{abstract}

$M$ arijuana is the illicit drug used most commonly during pregnancy. ${ }^{1,2}$ Gravidas who use marijuana differ from women who do not: they are more likely to be African-American, less educated, unmarried, or poor. ${ }^{3}$ Use of other substances, including alcohol, tobacco, and other illicit drugs is more likely. ${ }^{4,5}$ Aspects of pregnancy outcome, including gestational age at delivery and infant birth weight, have received considerable evaluation. $^{3-5}$

The relationship, if any, between marijuana use and sexually transmitted diseases has received little attention. A cross-sectional study of sexually active adolescents attending a general health organization teen clinic found a two-fold increase in sexually transmitted diseases in those patients who used marijuana at least once per week. ${ }^{6}$ Informa- tion concerning the relationship between sexually transmitted diseases, pregnancy, and marijuana use was found in a report primarily evaluating fetal growth. ${ }^{4}$ Differences between the marijuana user and control for the presence of either syphilis, gonorrhea, herpes, pelvic inflammatory disease or chlamydia infection did not exist. However, the criteria for diagnosis or testing schedules were not provided. Another study, also addressing low birth weight, found no difference in isolation of $C$. trachomatis between patients who used or did not use marijuana. ${ }^{7}$ Other sexually transmitted diseases were not considered.

Our population previously has been identified as having significant risk for both sexually transmitted infections and marijuana use. ${ }^{8,9}$ In this retrospective cohort study among pregnant women we

*Correspondence to: Dr. Joseph M. Miller, Jr., Department of Obstetrics and Gynecology, Louisiana State University Health Sciences Center, 1542 Tulane Avenue, New Orleans, Louisiana 70112-2822. 
evaluated the relationship between marijuana use and sexually transmitted infection.

\section{SUBJECTS AND METHODS}

Between January 1, 1997 and January 15, 1998, 557 women who have been previously characterized entered prenatal care at an inner-city prenatal program serving poor women. ${ }^{8,9}$ On initial visit patients provided a comprehensive history and were questioned about use of alcohol, tobacco, marijuana, cocaine, and other illicit drugs. Patients submitted urine samples that were screened for marijuana, cocaine, and other substances. Any patient who provided a history of illicit substance abuse or had a positive urine drug screen underwent monthly urine retesting. At initial visit patients also were screened with the following lab tests: venereal disease research laboratory result, hepatitis B surface antigen, human inmunodeficiency virus status (confirmed by Western blot), and DNA probe for $C$. trachomatis and $N$. gonorrhea. A Pap smear, evaluating the presence of human papilloma virus, was obtained as well. Screens for syphilis, HIV, gonorrhea, and chlamydia were repeated in the third trimester. Any patients with signs or symptoms of genital herpes were cultured for this virus. Patients with condyloma acuminata also were recorded, and were included in those reported with human papilloma virus.

In order to limit the potential confounding effect of cocaine or other illicit substances, two groups were selected for evaluation: 1) drug-free patients with negative histories and negative urine screens and 2) women who admitted to marijuana use during pregnancy or screened positive for marijuana, but who denied and tested negative for other illicit substances.

This research was approved by our institutional review board. Bivariate data were analyzed using $\mathrm{X}^{2}$ or Fisher's exact test, as appropriate. If a significant association was found, the magnitude also was expressed with odds ratios and $95 \%$ confidence limits. Continuous data were expressed as mean \pm standard deviation, but compared using Wilcoxin rank sums. Significance was set at 0.05 . Study size was determined assuming the prevalence of having one or more sexually transmitted infections to be $20 \%$ in drug-free pregnant women and $40 \%$ in marijuana-using patients. With $\beta=0.20$ and $\alpha=$ $0.05,46$ patients in each group would be required.
TABLE I. Description of patients

\begin{tabular}{lccc}
\hline & $\begin{array}{c}\text { Marijuana only } \\
\mathrm{n}=86^{\mathrm{a}}\end{array}$ & $\begin{array}{c}\text { Drug free } \\
\mathrm{n}=44 \mathrm{I}\end{array}$ & $\mathrm{P}$ \\
\hline Age $\geq 20$ years & $50(58 \%)$ & $243(55 \%)$ & n.s. \\
Black & $84(98 \%)$ & $433(98 \%)$ & n.s. \\
Parity $>1$ & $56(65 \%)$ & $245(56 \%)$ & n.s. \\
\hline
\end{tabular}

${ }^{a}$ n.s. = not significant

\section{RESULTS}

Marijuana use was found in 104 (18.7\%) of reviewed patients. Eighty-six were found to have used no other illicit substance and constituted the marijuana-only group. Sixteen patients provided a positive history for marijuana use, but had negative urine screens. Thirty-three women had positive urine screens only. The remaining 37 patients had positive histories and urine tests. The drug-free group consisted of 441 women with both a negative history and urine toxicology for illicit substances.

Patients in the two groups were similar with respect to age and race (Table 1 ). The 86 marijuanaonly patients were $21.0 \pm 4.2$ years vs. $21.1 \pm 4.4$ years for drug-free women, $P=$ n.s. There was no significant difference in the prevalence of multiparity. However, marijuana-using women were more likely to have a history of a prior sexually transmitted disease, $45 \%$ vs. $26 \%, P<0.001$, odds ratio $=2.3(1.4-3.7)$.

During pregnancy, the most common sexually transmitted diseases were chlamydia and gonorrhea. No differences between the marijuana-only and drug-free groups were found for any of the reported sexually transmitted diseases (Table 2). When the occurrence of any sexually transmitted infection was considered, $21 \%$ of the marijuanausing patients and $24 \%$ of the drug-free patients were so identified. The difference was not statistically significant.

\section{DISCUSSION}

Sexually transmitted diseases do not appear to be present more often in pregnant women whose illicit drug use is limited to marijuana than in drugfree women. The overall infection rate was not different. Differences for individual diseases also appear to be absent, although sample size is clearly inadequate to identify the small differences which may be present. For example, 539 patients in each group would need to be evaluated before the ob- 
TABLE 2. Occurrence of sexually transmitted disease and marijuana use during pregnancy

\begin{tabular}{lccc}
\hline & $\begin{array}{c}\text { Marijuana only } \\
\mathrm{n}=86\end{array}$ & $\begin{array}{c}\text { Drug free } \\
\mathrm{n}=44 \mathrm{I}\end{array}$ & $\mathrm{P}$ \\
\hline Gonorrhea & $6(7 \%)$ & $15(3 \%)$ & n.s. \\
Chlamydia & $13(15 \%)$ & $81(18 \%)$ & n.s. \\
Syphilis & $2(2 \%)$ & $12(3 \%)$ & n.s. \\
$\mathrm{HIV}^{\mathrm{b}}$ & $0(0 \%)$ & $2(1 \%)$ & n.s. \\
$\mathrm{HBsAg}^{\mathrm{c}}$ & $1(1 \%)$ & $0(0 \%)$ & n.s. \\
$\mathrm{HPV}^{\mathrm{d}}$ & $3(3 \%)$ & $8(2 \%)$ & n.s. \\
Herpes & $0(0 \%)$ & $8(2 \%)$ & n.s. \\
Any sexually transmitted & & & \\
\multicolumn{1}{c}{ disease } & $18(21 \%)$ & $104(24 \%)$ & n.s. \\
\hline
\end{tabular}

${ }^{a}$ n.s. = not significant

bHIV = human immunodeficiency virus

${ }^{\mathrm{CHBsAg}}=$ hepatitis $\mathrm{B}$ surface antigen

${ }^{\mathrm{d}} \mathrm{HPV}=$ human papilloma virus

served differences for gonorrhea ( $3 \%$ vs. $7 \%$ ) would have sufficient power to exclude type II error.

Sexually transmitted diseases are common in our patient population. Disease prevalence is similar to that found in other reviews we have conducted. Among non-cocaine-using control patients, $4 \%$ were found to have syphilis and 3\% to have gonorrhea. ${ }^{10}$ About $15 \%$ of pregnant women in our program tested positive for chlamydia. ${ }^{11} \mathrm{HIV}$, herpes, and hepatitis B are uncommon. ${ }^{8}$ We believe the current findings are representative of our patients, and more specifically, the observations in our control group are consistent with what was expected.

Limitations of the study include only a single interview for substance abuse and only a single urine screen for most patients. Screening and test results from delivery are not reported. Frequency or amount of drug use, an important parameter in the report of Boyce et al. ${ }^{6}$ was not documented. The inclusion of all users (including less frequent users) may dilute a potential relationship. Another limitation is the nature of the population reported. Our study evaluated only women enrolled in prenatal care; the influence of absent prenatal care is uncertain. Comparison to nonpregnant adolescents is also problematic and extension to other groups may be inappropriate.

Our study population carries significant risk for sexually transmitted diseases, as expected, since they are young and sexually active. The data reinforce the prior, but limited, observation of lack of differences between marijuana using and nonusing prenatal patients as suggested by Zuckerman's report. ${ }^{4}$ In our review, history of prior sexually transmitted infection was observed more often in the marijuana-using group as is consistent with prior observations of nonpregnant adolescents. ${ }^{6}$ Nevertheless, when considering a pregnant population such as the one we report, the conclusion we draw is that marijuana use alone is unassociated with sexually transmitted infection.

\section{REFERENCES}

1. Chasnoff IJ, Landress HJ, Barrett ME. The prevalence of illicit-drug or alcohol use during pregnancy and discrepancies in mandatory reporting in Pinellas County, Florida. N Engl J Med 1990;322:1202-1206.

2. Lake MF, Angel JL, Murphy JM, et al. Patterns of illicit drug use at the time of labor in a private and public hospital. J Perinatal 1992;12:134-136.

3. Day N, Sambamoorthi U, Taylor P, et al. Prenatal marijuana use and neonatal outcome. Neurotoxicol Teratol 1991;13:329-334.

4. Zuckerman B, Frank D, Hingson R, et al. Effects of maternal marijuana and cocaine use on fetal growth. $\mathrm{N}$ Engl J Med 1989;320:762-768.

5. Witter FR, Niebyl JR. Marijuana use in pregnancy and pregnancy outcome. Am J Perinatal 1990;7:36-38.

6. Boyce CB, Shafer M-A, Teitle E, et al. Sexually transmitted diseases in a health maintenance organization teen clinic. Arch Pediatr Adolesc Med 1999;153:838844.

7. Shiono PH, Klebanoff MA, Nugent RP, et al. The impact of cocaine and marijuana use in low birth weight and preterm birth: A multi-center study. Am J Obstet Gynecol 1995;172:19-27.

8. Boudreaux MC, Miller JM Jr, Wightkin JC, et al. Collaborative care for low and high-risk obstetric patients: an evolving model. J Perinatal 1997;19:33-36.

9. Mvula MM, Miller JM Jr. A comparative evaluation of collaborative prenatal care. Obstet Gynecol 1998;91: 169-173.

10. Miller JM Jr, Boudreaux MC, Regan FA. A case-control study of cocaine use in pregnancy. Am J Obstet Gynecol 1995;172:180-185.

11. Miller JM Jr. Recurrent chlamydial colonization during pregnancy. Am J Perinatal 1998;15:307-309. 


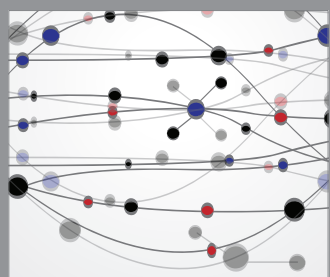

The Scientific World Journal
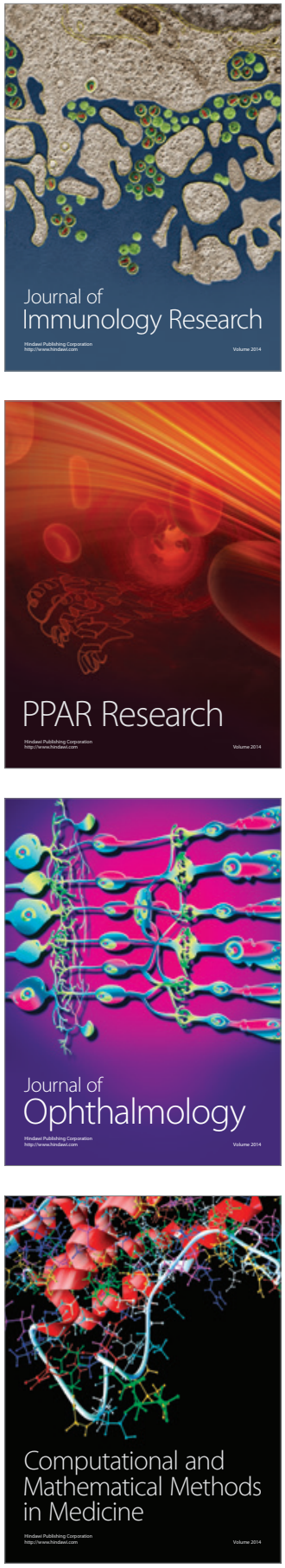

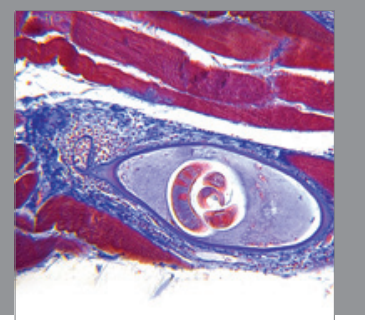

Gastroenterology

Research and Practice
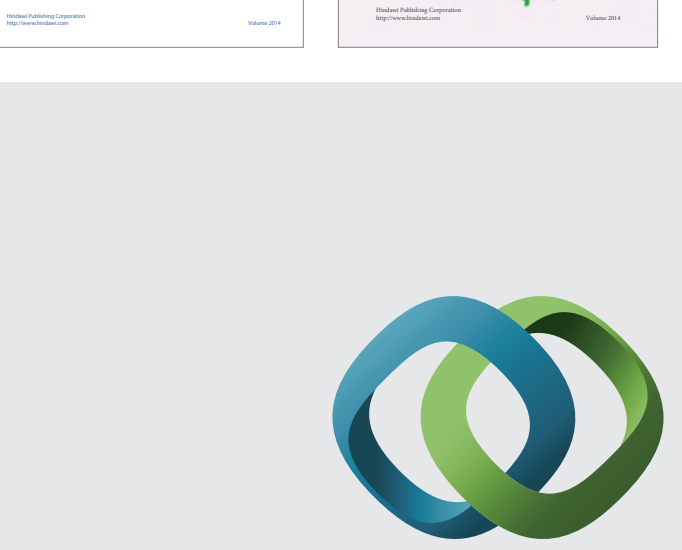

\section{Hindawi}

Submit your manuscripts at

http://www.hindawi.com
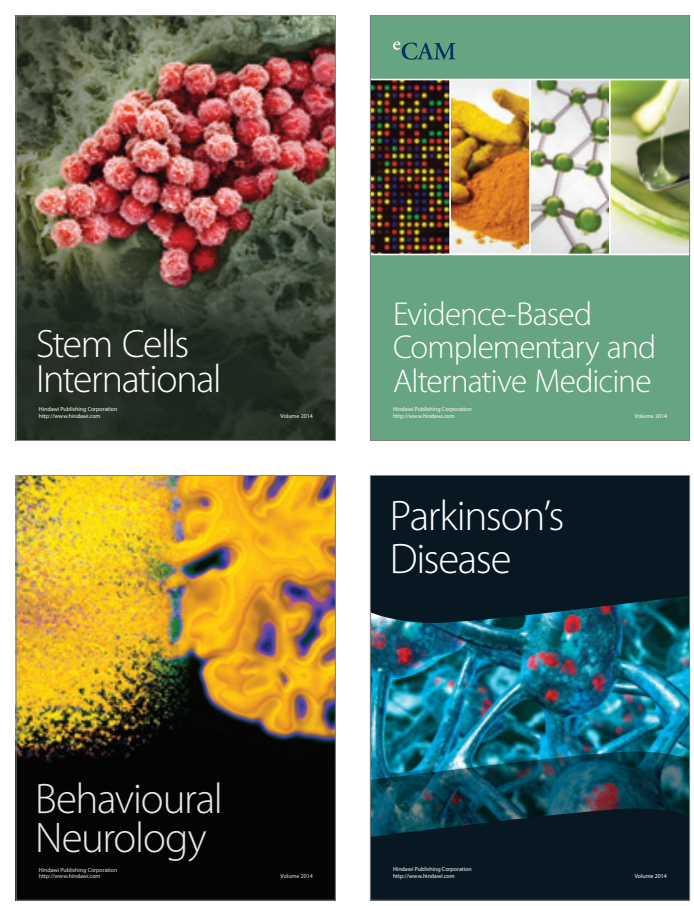

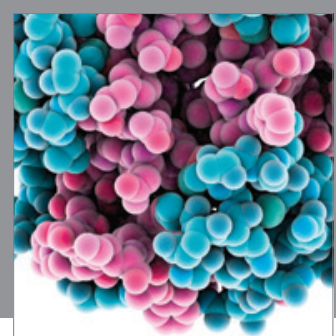

Journal of
Diabetes Research

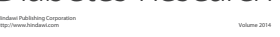

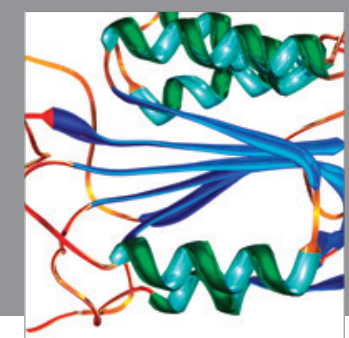

Disease Markers
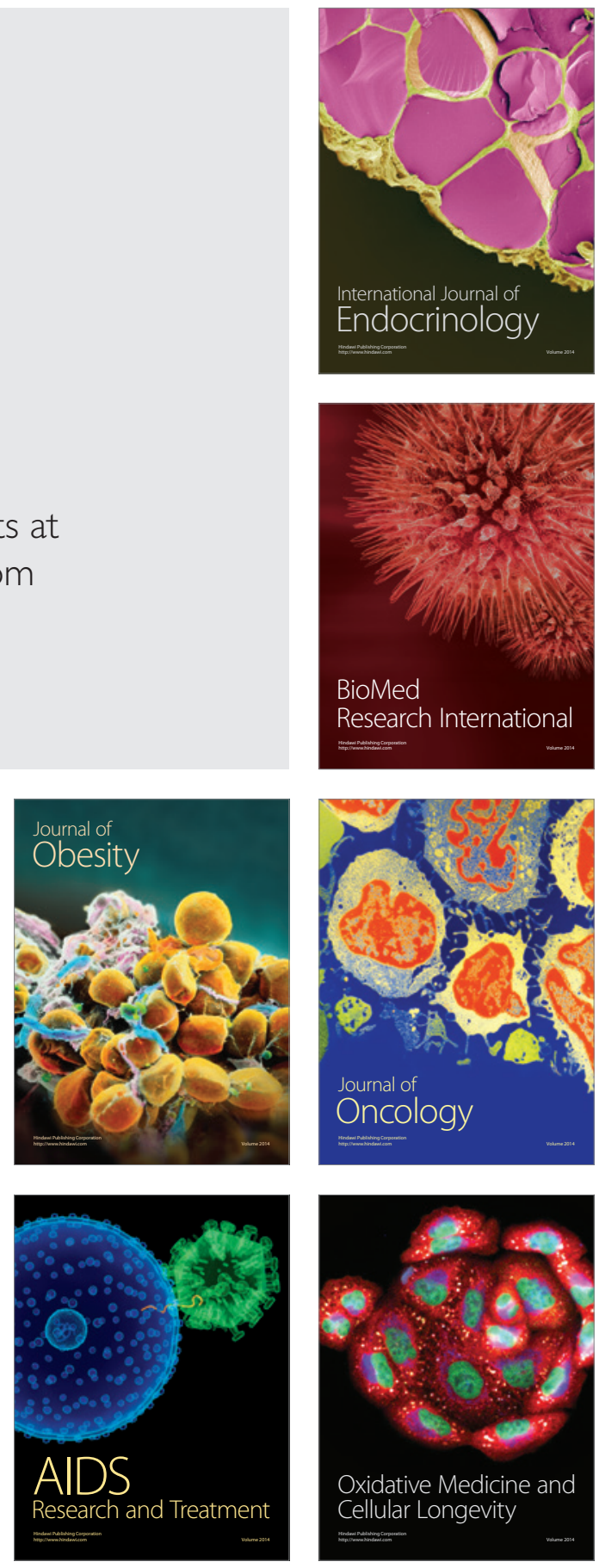